\title{
A new strategy for dendritic lead oxide nanostructures using electrochemical methods
}

\author{
Hamid Reza Ebrahimi ${ }^{{ }^{*}}$, Sajjad Damiri ${ }^{1}$ and Hassan Yousofian Varzaneh ${ }^{1}$ \\ ${ }^{1}$ Department of Chemistry, Majlesi Branch, Islamic Azad University, Isfahan, Iran \\ hebrahimi2010@gmail.com*
}

\begin{abstract}
In this study we describe the shape-controlled synthesis of lead oxide nanodendrites (NDs) via electrochemical methods in aqueous solution of $\mathrm{PbNO}_{3}$ with the assistance of polyethylene glycole (PEG) as a soft template, to achieve a superior active electrodes with enhanced charge storage capacity compared to conventional bulk $\mathrm{PbO}$ electrodes. The effects of the growth conditions such as concentrations of the reagents and applied potentials on the morphology and structure of as-prepared tree-like nanostructures have also been investigated by scanning electron microscopy (SEM), and X-ray diffraction (XRD). The morphology of the nanostructures mainly depends on the adjustable driving force of electrodeposition, such as the potential, the concentration of lead precursor $\left(\mathrm{Pb}^{2+}\right)$, and the presence of inert electrolyte ions, while being modulated by PEG that contributes mainly to the finer structure in the shape-controlled synthesis. This unique structure provides an effective method for increasing the efficiency and capacity of the active material in lead-acid batteries.
\end{abstract}

Keywords: Electrodeposition, Lead oxide, Synthesis, Polyethylene glycol

\section{Introduction}

Nanotechnology has recently become one of the most exciting forefront fields in the design of various important electrodes applied in the electrochemical systems due to their unique size and properties (Yu et al., 2003; Eftekhari, 2008; Ensafi et al., 2011). Nowadays, traditional macro-electrodes are being replaced with their nanostructure analogues. The predominant advantages of using nanostructure electrodes compared to typical macro-electrodes is their large effective surface area, considerable mass transport, high catalytic activity, and their ability to exert control over the local environment at the electrode surface (Campbell et al., 2010; Sun, 2010). Also, the existing of very sharp edge sites and defects on the nanostructures can significantly reduce the overpotential of electrochemical reactions to become more reversible than that displayed by the same material in a conventional form (Banks et al., 2006; Rezaei \& Damiri, 2010). Recently, considerable efforts have been focused on the design, synthesis, and application of high ordered inorganic crystals with specific sizes, shapes, and hierarchies. Different kinds of nanomaterials, such as metals (Yu et al., 2003), semiconductors, oxides (Polshettiwar et al., 2009), and carbon nanotubes (Valcárcel et al., 2007), and different nanostructures such as nanowire (Roberts \& Kelley, 2007; Tyagi et al., 2009), flower-like (Liu et al., 2005; Jena \& Raj, 2007), urchin-like (Zhang et al., 2006), mushroom-like (Shiigi et al., 2009), and dendrite-like (Wen et al., 2006; Zhou et al., 2006; Zhang et al., 2008) have been reported based on different advanced strategies.

The intrinsic properties of the nanostructures are determined by their size, shape, morphology, composition, and crystallinity (Rezaei \& Damiri, 2010; Kiani et al., 2010; Lei et al., 2011). The excellent nanodendritic structure of lead oxide, as a new morphology of the electroactive material in lead acid

Research article

(C) Indian Society for Education and Environment (iSee) batteries, with significantly high specific surface area compared to spherical microparticles can be a promising choice for the modifying of the performance of conventional lead acid batteries or other electrochemical systems. Lead-acid batteries developed as widespread articles of commerce in over a century. Relatively good specific power has caused widespread use of lead-acid batteries in starting, lighting and ignition of engine (SLI) purposes for vehicular (e.g., automotive, marine and aviation) applications. The substantial growth in new demands, such as telecommunication networks, electronics, and computers has raised new challenges for lead acid batteries. The main requirements for these batteries are high power and discharge rates, a long life and, and a substantial weight reduction (Bhardwaj et al., 2000; Chen, 2000). In recent years, there has been an increase in the amount of trends focusing on nanotechnological methods to prepare nanoparticle of active material in batteries with extended advantages.

In previous reports, spray pyrolysis method (Konstantinov et al., 2006) and chemical reaction methods (Wang et al., 2001; Sadeghzadeha et al., 2010) were used for synthesis of lead oxide nanoparticles. Dendritic patterns are essential phenomena that are observed in non-equilibrium conditions for metallurgic, inorganic, and organic crystal growth; hence provide a natural framework for the study of disordered systems (Dick et al., 2004). The diffusion-limited aggregation (DLA) model and anisotropic crystal growth are widely used to explain and analyze these growth phenomena (Witten \& Sander, 1981; Jacob \& Garik, 1990).

Here, we demonstrate a facile route for the synthesis of highly crystalline dendritic lead oxide nanostructures with preferred crystal growth directions by electrodeposition method and by employing polyethylene glycol (PEG) as a soft template. In the electrodeposition methods, some processes such as kinetic anisotropy in
"Lead oxide nanodentrite" http://www.indjst.org
H.R.Ebrahimi et al. Indian J.Sci.Technol. 
the reduction of electroactive ions (Barkey et al., 1995; Rezaei \& Damiri, 2010) and the lack of electrolyte play an important role in the formation of structure (Zheng et al., 2007). The obtained lead oxide nanostructures were characterized by electrochemical techniques and the quality of the products in the various synthesis conditions was investigated by scanning electron microscopy (SEM) and X-ray diffraction (XRD).

\section{Experimental \\ Apparatus and reagent}

All chemicals, unless mentioned otherwise, were of analytical grade and were used as received. Lead nitrate 99.9\%) and PEG-2000 (polyethylene glycol 2000) were purchased from Aldrich company. All aqueous solutions were made with demineralized water, which was further purified with a Milli-Q system (Millipore) with the resistivity not less than $18.0 \mathrm{M}$ at $25 \mathrm{C}$.

Electrochemical measurements were carried out by a conventional three-electrode cell, using a planar glassy carbon electrode (GCE) as the working electrode, a graphite electrode, spaced with 1-25 mm from GCE, as the counter electrode, and a platinum wire as the quasireference electrode (PtQRE) immersed directly in the lead plating solution, except for lead-free control experiments, which were performed by using a saturated $\mathrm{Hg} / \mathrm{HgCl}_{2}$ electrode.

\section{Preparation and characterization of $\mathrm{PbO}$ nanodendrites}

The potentiostatic deposition of lead oxide NDs was accomplished on the GC electrode by pulsing the potential from $0.0 \mathrm{~V}$ to $-1.5 \mathrm{~V}$ vs. PtQRE (electrodeposition potential; $E_{\mathrm{D}}$ ), for a period of $20.0 \mathrm{~min}$. Here, $1.0 \mathrm{mM}$ lead nitrate (Aldrich, 99.9\%) solution was prepared into a homodisperse mixture of PEG-2000 (polyethylene glycol 2000)/ $\mathrm{H}_{2} \mathrm{O}(2.0$ gram in $100.0 \mathrm{~mL}$ water) and it was used as the electrodeposition solution. Finally, the lead oxide nanocrystals deposited on the working electrode were thoroughly washed with acetone droplets and water, and dried in ambient conditions.

The final products were characterized by powder Xray diffraction (XRD) on a Philips Xpert-MPD Model 3040 $\mathrm{X}$-ray diffractometer equipped with $\mathrm{Cu} \mathrm{K}$ radiation. Also, the scanning electron microscopy (SEM) images were recorded with a Philips XL Model 30 microscope.

\section{Results and discussion}

\section{Electrochemical deposition studies}

The potentiostatic deposition of lead nanocrystallites on GC electrode was accomplished by pulsing of the potential in the range of $0.0 \mathrm{~V}$ to $-3.0 \mathrm{~V}$ vs. PtQRE for $1200 \mathrm{~s}$ (see inset of Fig. 1). Representative current-time transient for this electrodeposition process has been shown in Fig. 1. Here, firstly, the $\mathrm{Pb}^{2+}$ precursors are reduced to form lead metal nanoparticles, which can be easily oxidized to $\mathrm{PbO}$ in the presence of oxygen and the synthesis conditions. This chronoamperometric behavior for the reduction of $\mathrm{Pb}^{2+}$ ions in the $\mathrm{PEG} / \mathrm{H}_{2} \mathrm{O}$ solution, with GC as the working electrode and a PtQRE as the reference electrode shows the characteristic features of the diffusion-controlled electrodeposition.

Fig. 1. Current-time signal in the electrodeposition process of $\mathrm{PbO} \mathrm{NDs}$ for $2.0 \mathrm{mM} \mathrm{PbNO}_{3}$ in $\mathrm{PEG} / \mathrm{H}_{2} \mathrm{O}$

(2.0 g: $100 \mathrm{~mL}$ water) solution. Inset shows a typical electrode potential-time route applied for this experiment.

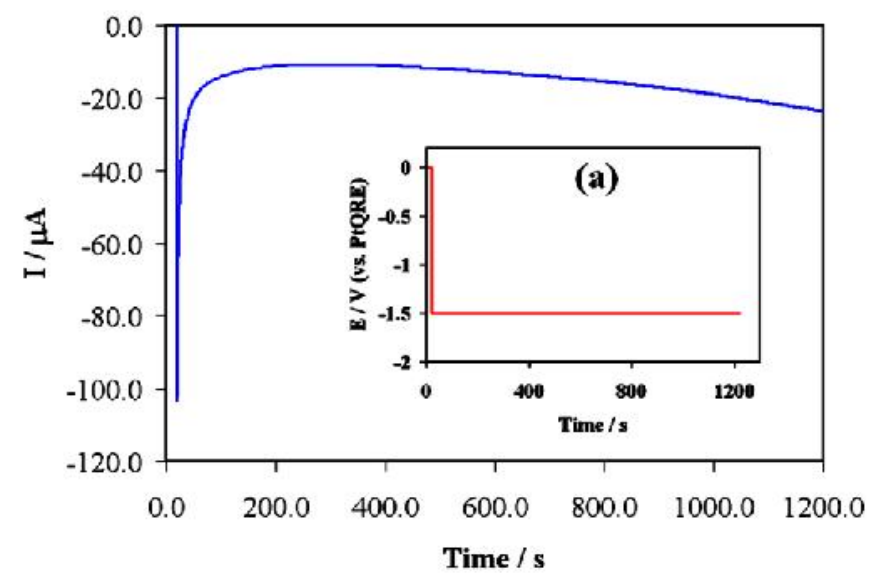

Fig. 2. Electrochemical reduction (a) and oxidation (b) voltammograms of PbO NDs synthesized in the conditions similar to Fig. 1.
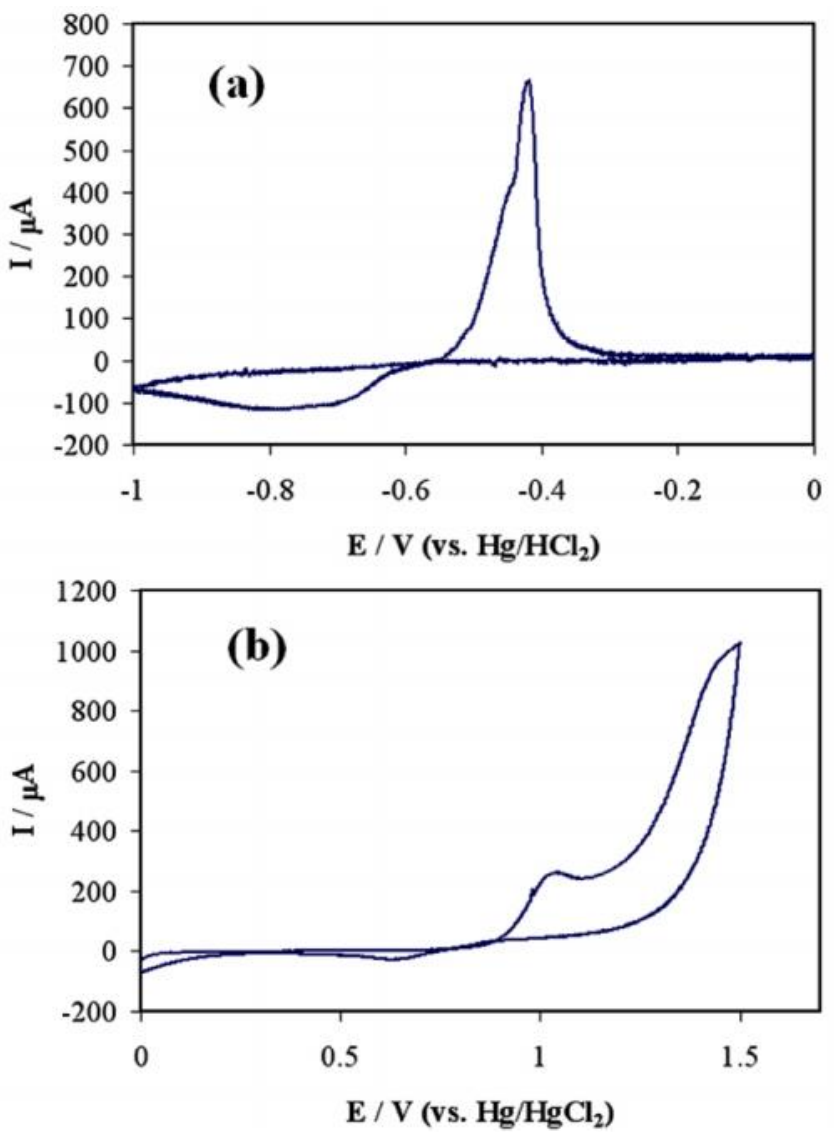

The voltammetric studies (not shown) shows that the electrodeposition reaction take place more readily in the second and subsequent scans and their reduction peak is 
Fig. 3. Typical SEM images of the products obtained in the conditions of; a) $E_{D}=-1.5 \mathrm{~V}$ (vs. PtQRE) and $2.0 \mathrm{mM} \mathrm{PbNO}_{3}$ in $P E G$ $1 / \mathrm{H}_{2} \mathrm{O}$ (2.0 g: $100 \mathrm{~mL}$ water) solution, b) as (a) without $P E G$, c) as (a) with $E_{D}=-3.0 \mathrm{~V}$, and d) as (a) with $0.1 \mathrm{mM} \mathrm{PbNO}_{3}$
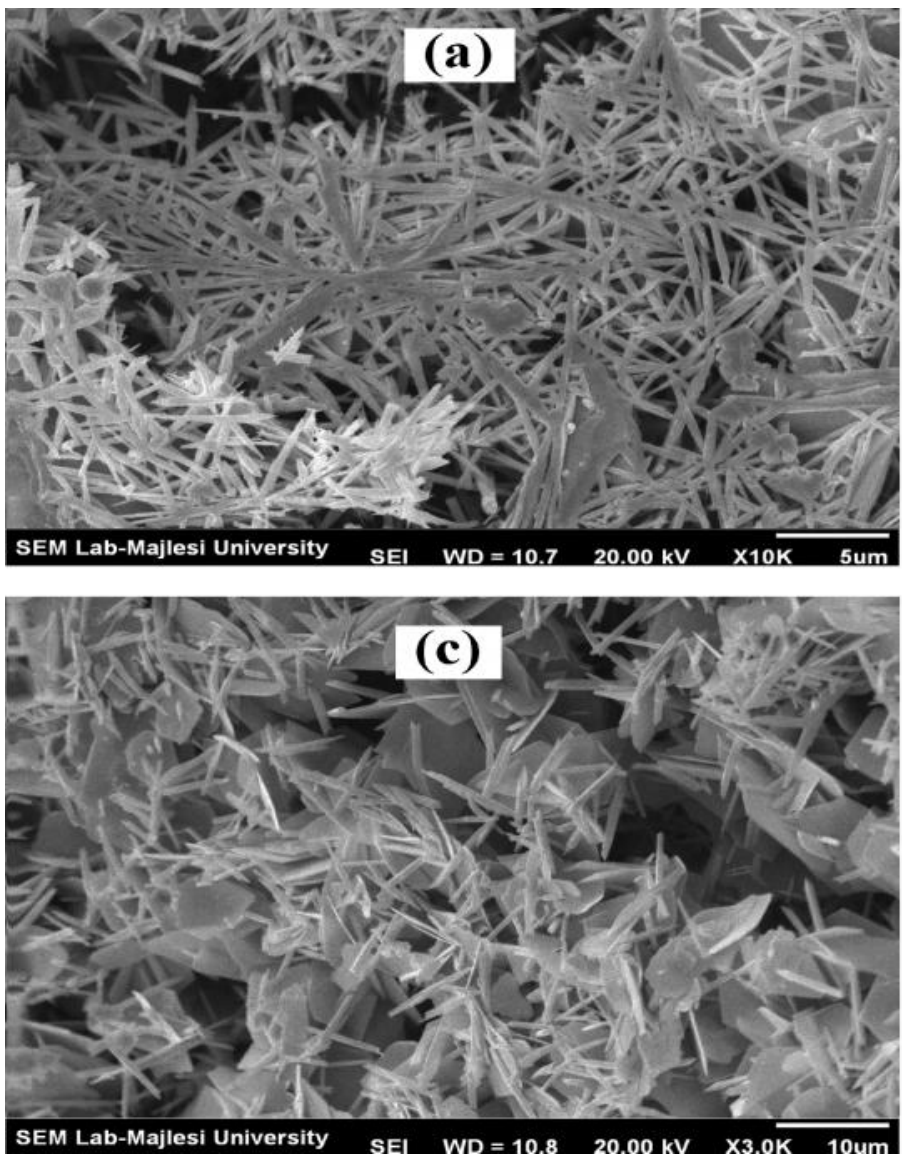

positively shifted with respect to the first scan, due to facilitating the nucleation and deposition process.

The electrochemical behavior of the lead oxide NDs electrode was characterized by cyclic voltammetric studies. According to the voltammograms represented in Fig. 2a, this electrode, in the $\mathrm{KCl}$ electrolyte with $\mathrm{pH} 7.0$, shows two sharp redox peaks in the negative potentials, located at -0.42 and near to $-0.7 \mathrm{~V}$ versus $\mathrm{Hg} / \mathrm{HgCl}_{2}$. These redox peaks reflect the electrochemical reduction of $\mathrm{PbO}$ and the oxidation of $\mathrm{Pb}$. Dendritics lead oxides can also oxidizes to $\mathrm{PbO}_{2}$ in the positive potentials (> $+0.9 \mathrm{~V}$ ), then convert to $\mathrm{PbO}$ in the reverse potential scans (Fig. 2b). The potential ranges in positive and negative direction were limited by the evolution of oxygen and hydrogen gases (Rezaei \& Damiri, 2005).

\section{Morphological characterization of the prepared $\mathrm{PbO}$ nanodendrites}

Typical SEM images of the final products exhibit that $\mathrm{PbO}$ crystals obtained under the mentioned experimental conditions possess a nanodendritic structure (see Fig. 3a-d), providing relatively high specific surface area compared to conventional microparticles. Also, X-ray diffraction (XRD) pattern of NDs (Fig. 4) on the GCE support, synthesized at $2.0 \mathrm{mM}$ lead nitrate for $20.0 \mathrm{~min}$
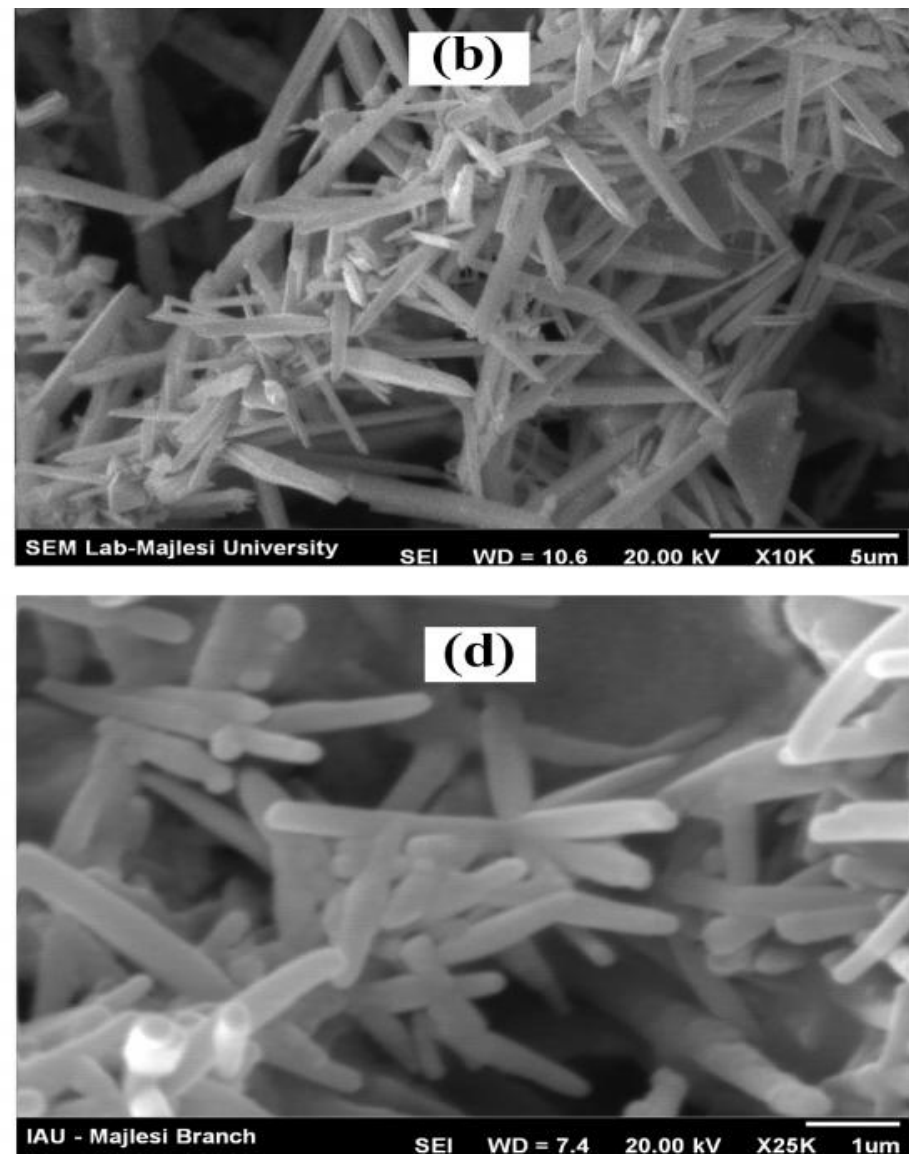

of electrodeposition time, confirm the diffraction characteristic of orthorhombic PbO crystals (JCPDS 381477 XRD card number). As can be seen in the Fig 3a, the individual $\mathrm{PbO}$ dendrites have two and three dimensional (3D) structures with some trunks (long axes) and branches (short axes). The dendritic crystals grow along a preferential direction, and the nanorods in each branch are in the same plane. The diameter of the branches is around 100-300 $\mathrm{nm}$ and its length up to 5-10 $\mu \mathrm{m}$. The length of the trunks can reach $30 \mu \mathrm{m}$. More interestingly, during the growth process of lead oxide nanocrystal, each branch can also be a trunk to support

Fig. 4. A typical X-ray diffraction patterns of the nanostructures

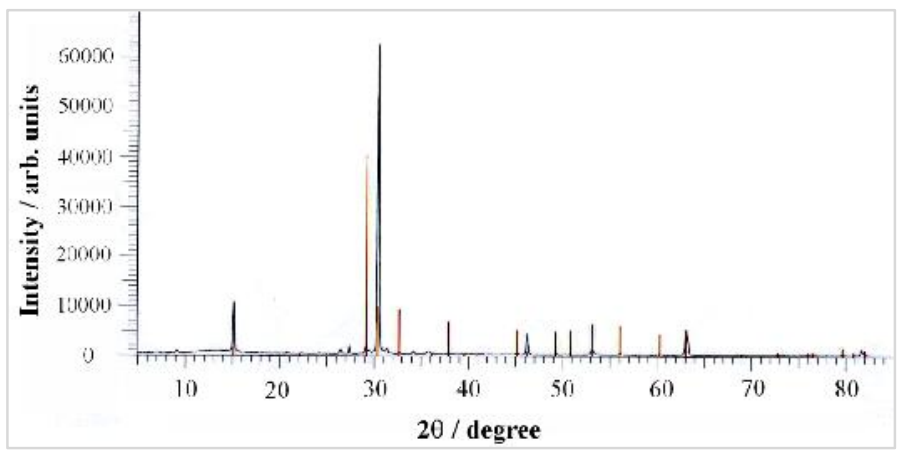

Research article

CIndian Society for Education and Environment (iSee)
"Lead oxide nanodentrite" http://www.indjst.org
H.R.Ebrahimi et al. Indian J.Sci.Technol. 
Fig. 5. SEM images of the PbO nanostructures obtained in the conditions of; a) $E_{D}=-2.5 \mathrm{~V}$ (vs. PtQRE) and $1.0 \mathrm{mM}$ $\mathrm{PbNO}_{3}$ in $\mathrm{PEG} / \mathrm{H}_{2} \mathrm{O}$ (2.0 g: $100 \mathrm{~mL}$ water) solution, b) as (a) with $E_{D}=-1.5 \mathrm{~V}$ and $1.0 \mathrm{mM} \mathrm{PbNO}$ in $\mathrm{PEG} / \mathrm{H}_{2} \mathrm{O}(5.0 \mathrm{~g}: 100 \mathrm{~mL}$ water) solution

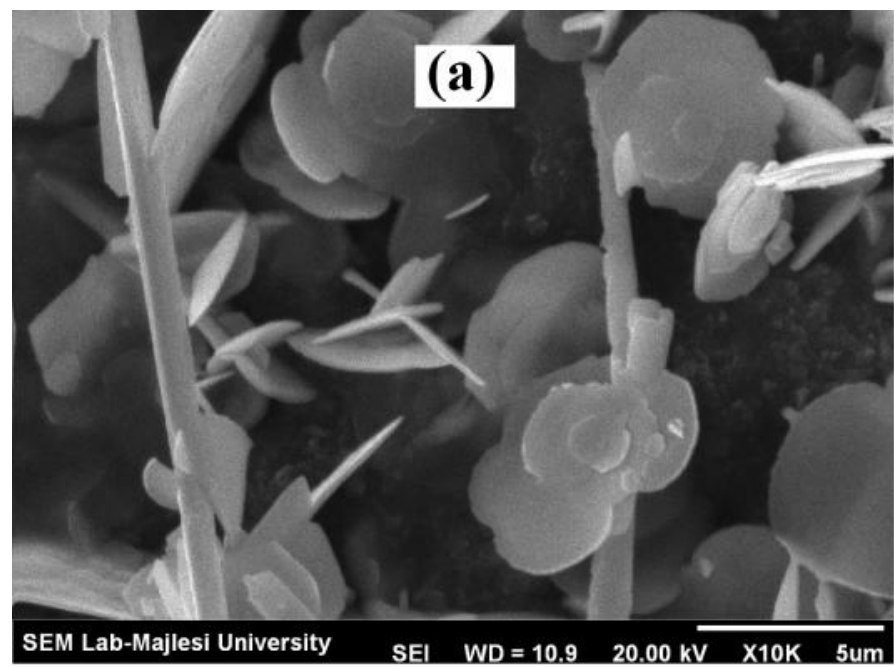

the growth of lead oxide nanorods. Thus, the selfreplication makes this kind of lead oxide nanostructures have a more advanced structure.

It is interesting that in the free electrolyte conditions and the absence of PEG template, the growth process lead to non-uniform dendritic structures as well (see Fig. $3 b$ ). If we use some inert salts, such as $\mathrm{K}_{2} \mathrm{SO}_{4}$, as an inert electrolyte, there will not appear dendritic structures, and the deposition mechanism goes to the formation of large microparticles and sheet-like structures (not shown).

In general, the morphology of the nanostructures depends strongly on the electrodeposition potential $\left(E_{\mathrm{D}}\right)$, presence of electrolyte, and the ratio of PEG polymer to $\mathrm{Pb}^{2+}$. PEG can mainly modulate structure to the finer and well-arranged morphology in the shape-controlled synthesis. According to the Fig. 3, by controlling reaction conditions, not only 3D PbO nanostructures composed of dendritic rod, but also dendritic sheet was successfully prepared. The product morphology is largely determined by the applied potential since it decides the electrochemical driving force in the constant potential mode. In the potentials range of -1.0 to $-2.0 \mathrm{~V}$ (vs. PtQRE), it is observed uniform dendritic rods with small dimensions and numerous side branches. But, in the higher deposition potential, according to the Fig. 3c, there obtain high density dendritic sheets with larger dimensions and higher density. Also, the morphology of the resultant particles is very sensitive to the concentrations of $\mathrm{PbNO}_{3}$ and PEG. The high amount of lead precursor $\left(>5.0 \mathrm{mM} \mathrm{PbNO}_{3}\right.$ ) shows a behavior similar to high potential conditions. On the other hand, a sample prepared with a low amount of $\mathrm{PbNO}_{3}$ (Fig. 1d) shows the dendritic rod-like morphology with lower dimensions and density. Also, by reduction of PEG concentration ( $<0.5 \mathrm{~g}$ PEG in $100.0 \mathrm{~mL}$ water), the morphology of nanostructures deviates from dendritic shape to the isotropic and sheet like structures. It is quite obvious that PEG is very crucial for the formation of lead

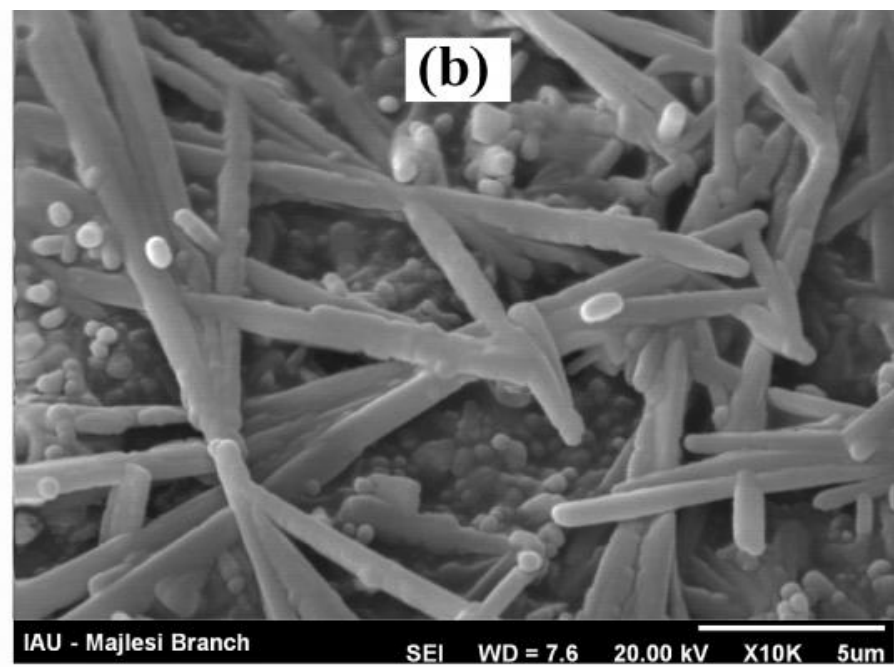

oxide dendrites, and it has a structure-directing effect in the electrodeposition process. As shown in the Fig. 5, other experiments show that by modulating the electrodeposition conditions, it can be synthesized some attractive structures such as rod-like and flower-like nanosheets.

It is believed that the growth mechanism of the dendritic or tree-like structures follows on the basis of a diffusion-limited aggregation (DLA) mode (Barkey et al., 1995; Witten \& Sander, 1981; Zheng et al., 2007) explained the formation of dendritic morphology based on the anisotropy created by the elementary chemical reaction equilibrium involved in the deposition. Here we can introduce an interfacial anisotropy by complexing of the $\mathrm{Pb}^{2+}$ in the presence of PEG. Initially, interfacial free energy is constant due to the planar substrate surface; however, once the deposition of $\mathrm{Pb}$ starts anisotropy is formed for $\mathrm{Pb}^{2+} / \mathrm{PEG}$ complexes, because the adsorption energy of the complexes may vary drastically depending on the different planes on which the complex is adsorbed compared to the free $\mathrm{Pb}^{2+}$ ions (Fig.3-4).

\section{Electrochemical impedance spectroscopy studies}

Electrochemical impedance spectroscopy (EIS) can provide some information about the charge storage capacitance of the materials. Typical EIS results are shown in Fig. 6 where it can be seen that the Nyquist plots consist of a semicircle portion observed at higher frequency range corresponding to the electron-transferlimited process and a linear part at lower frequencies representing the diffusion limited process. The EIS data were approximated using FRA 4.9 software and complex nonlinear least square (CNLS) approximation method, from which electron transfer kinetics as charge transfer resistance $\left(R_{\mathrm{ct}}\right)$, solution resistance $\left(R_{\mathrm{s}}\right)$, constant phase element (CPE) and a mass transfer element $W$ (Warburg impedance) were extracted. The EIS data obtained for the electrodes were fitted to the modified Randles' model
Research article

Clndian Society for Education and Environment (iSee)
"Lead oxide nanodentrite" http://www.indjst.org
H.R.Ebrahimi et al. Indian J.Sci.Technol. 
Fig. 6. Nyquist plots of the impedance $\left(Z_{\text {Im }} v s . Z_{R e}\right)$ for a) microparticles and b) nanodendritic lead oxide in $1.0 \mathrm{M} \mathrm{H}_{2} \mathrm{SO}_{4}$ and the potential of $+0.8 \mathrm{~V}$ as dc-offset. Inset shows the corresponding equivalent circuit.

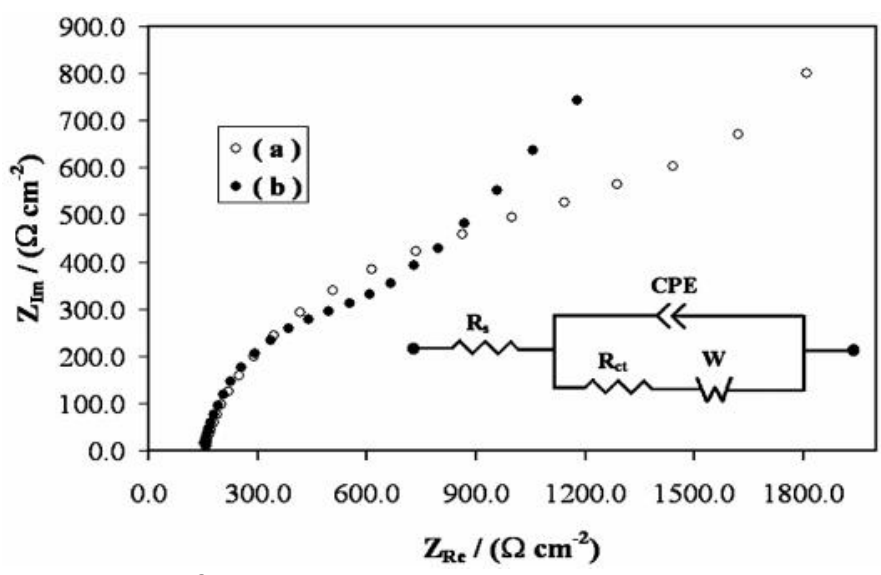

in which perfect capacitance element was replaced by frequency-dependent constant phase element. Large microparticles (10-50 $\mathrm{mM}$ ) obtained in the $10.0 \mathrm{mM}$ $\mathrm{PbNO}_{3}$ and the $E_{\mathrm{D}}=-3.0 \mathrm{~V}$ (vs. PtQRE) without using $P E G$ template. The results indicate that the values of CPE capacitance of NDs and microparticles are 31.1 and $10.5 \mathrm{mF} \mathrm{cm}^{2}$, respectively. This improvement in the capacitance of nanostructures may be due to the fact that $\mathrm{PbO}$ NDs have a larger efficient active surface area with numerous active sites for the electrochemical reactions.

\section{Conclusion}

Shape-controlled synthesis of lead oxide nanostructures, composed of dendritic rods or sheets, was investigated by a simple PEG-assisted electrodeposition technique. It is found that $E_{\mathrm{D}}$ and the concentration of $\mathrm{PEG}$ and $\mathrm{PbNO}_{3}$ play an important role in controlling the growth morphology of the lead oxide particles. Low concentrations of polymer yield isotropic particles; whereas, its higher concentrations after an extended period, give particles in the shape of dendrites. This work provides a simple route for a controllable synthesize other electrodeposited nanostructures with various shapes. The electrodes prepared with nanodendritic $\mathrm{PbO}$ compared to conventional microparticles, showed excellent behavior for improving of the electrochemical performance and charge storage capacity.

\section{Acknowledgements}

The authors wish to thank Islamic Azad UniversityMajlesi Branch for support of this work.

\section{References}

1. Eftekhari A (2008) Nanostructured materials in electrochemistry. Wiley-VCH Verlag $\mathrm{GmbH} \& \mathrm{Co}$. KGaA: Weinheim.
Vol. 5 No. 9 (Sep. 2012)

ISSN: 0974- 6846

2. Ensafi $A A$, Karimi-Maleh $H$, Ghiaci $M$ and Arshadi $M$ (2011) Characterization of Mn-nanoparticles decorated organo-functionalized $\mathrm{SiO} 2-\mathrm{Al} 2 \mathrm{O} 3$ mixedoxide as a novel electrochemical sensor: application for the voltammetric determination of captopril, $J$. Mater. Chem. 21, 15022-15030.

3. Yu A, Liang Z, Cho J and Caruso F (2003) Nanostructured electrochemical sensor based on dense gold nanoparticle films. Nano Lett. 3, 12031207.

4. Campbell FW and Compton RG (2010) The use of nanoparticles in electroanalysis: an updated review. Anal. Bioanal. Chem. 396, 241-259.

5. Sun P (2010) cylindrical nanopore electrode and its application to the study of electrochemical reaction in several hundred attoliter volume. Anal. Chem. 82, 276-281.

6. Banks CE, Crossley A, Salter C, Wilkins SJ and Compton RG (2006) Carbon nanotubes contain metal impurities which are responsible for the "Electrocatalysis" seen at some nanotube-modified electrodes. Angew. Chem. Intl. Ed. 45, 2533-2537.

7. Rezaei B and Damiri S (2010) Fabrication of a nanostructure thin film on the gold electrode using continuous pulsed-potential technique and its application for the electrocatalytic determination of metronidazole. Electrochim. Acta. 55, 1801-1808.

8. Polshettiwar V, Baruwati B and Varma RS (2009) Self-assembly of metal oxides into three-dimensional nanostructures: synthesis and application in catalysis. ACS Nano. 3, 728-736.

9. Valcárcel M, Cárdenas S and Simonet BM, (2007) Role of Carbon Nanotubes in Analytical Science. Anal. Chem. 79, 4788-4797.

10. Tyagi P, Postetter D, Saragnese DL, Randall CL, Mirski MA and Gracias DH (2009) Patternable nanowire sensors for electrochemical recording of dopamine. Anal. Chem. 81, 9979-9984.

11. Roberts MA and Kelley SO (2007) Ultrasensitive detection of enzymatic activity with nanowire electrodes. J. Am. Chem. Soc. 129, 11356-11357.

12. Jena BK and Raj CR (2007) Synthesis of flower-like gold nanoparticles and their electrocatalytic activity towards the oxidation of methanol and the reduction of oxygen. Langmuir. 23, 4064-4070.

13. Liu YL, Yang $Y H$, Yang HF, Liu ZM, Shen $G L$ and $Y u$ RQ (2005) Nanosized flower-like ZnO synthesized by a simple hydrothermal method and applied as matrix for horseradish peroxidase immobilization for electrobiosensing. J. Inorg. Biochem. 99, 2046-2053.

14. Zhang $\mathrm{HL}$, Zhang $Y$, Zhang XG, Li F, Liu C, Tan J and Cheng HM (2006) Urchin-like nano/micro hybrid anode materials for lithium ion battery. Carbon. 44, 2778-2784.

15. Shiigi H, Morita R, Yamamoto $Y$, Tokonami S, Nakao $\mathrm{H}$ and Nagaoka $\mathrm{T}$ (2009) Self-organization of an organic-inorganic hybrid nanomushroom by a simple

Research article

(C)Indian Society for Education and Environment (iSee)
"Lead oxide nanodentrite" http://www.indjst.org
H.R.Ebrahimi et al. Indian J.Sci.Technol. 
synthetic route at the organic/water interface. Chem. Commun. 24, 3615-3617.

16. Zhang JC, Meng LJ, Zhao DB, Fei ZF, Lu QH and Dyson PJ (2008) Fabrication of dendritic gold nanoparticles by use of an ionic polymer template. Langmuir. 24, 2699-2704.

17. Wen $X, X i e ~ Y T$, Mak MWC, Cheung KY, Li XY, Renneberg $R$ and Yang $S$ (2006) Dendritic nanostructures of silver: facile synthesis, structural characterizations, and sensing applications. Langmuir. 22, 4836-4842.

18. Zhou Q, Wang S, Jia N, Liu L, Yang J and Jiang Z (2006) Synthesis of highly crystalline silver dendrites microscale nanostructures by electrodeposition. Mater. Lett. 29-30, 3789-3792.

19. Rezaei B and Damiri S (2010) Electrodeposited silver nanodendrites electrode with strongly enhanced electrocatalytic activity. Talanta. 83 197-204.

20. Lei D, Zhang M, Hao Q, Chen L, Lia Q, Zhang E and Wang $T$ (2011) Morphology effect on the performances of $\mathrm{SnO} 2$ nanorod arrays as anodes for Li-ion batteries. Mater. Lett. 65, 1154-1156.

21. Kiani MA, Mousavi MF and Ghasemi S (2010) Size effect investigation on battery performance: Comparison between micro- and nano-particles of $\beta$ $\mathrm{Ni}(\mathrm{OH}) 2$ as nickel battery cathode material. J. Power Sources. 195, 5794-5800.

22. Bhardwaj RC and Than J (2000) Lead acid battery with thin metal film (TMF®) technology for high power applications. J. Power Sources. 91, 51-61.

23. Chen JS (2000) Development of VRLA batteries for high rate discharge applications. J. Power Sources. 85, 172-177.

24. Konstantinov $\mathrm{K}, \mathrm{Ng} \mathrm{SH}$, Wang JZ, Wang GX, Wexler $\mathrm{D}$ and Liu HK (2006) Nanostructured PbO materials obtained in situ by spray solution technique for Li-ion batteries. J. Power Sources. 159, 241-244.

25. Wang J, Zhong S,Wang GX, Bradhurst DH, lonescu M, Liu HK and Dou SX (2001) Electrochemical performance of nanocrystalline lead oxide in VRLA batteries. J. Alloys Comp. 327, 141-145.

26. Sadeghzadeha H, Morsali A, Yilmaz VT and Büyükgüngörc $\mathrm{O}$ (2010) Synthesis of $\mathrm{PbO}$ nanoparticles from a new one-dimensional lead(II) coordination polymer precursor. Mater. Lett. 64, 810813.

27. Dick KA, Deppert K, Larsson MW, Martensson T, Seifert W, Wallenberg LR and Samuelson L (2004) Synthesis of branched 'nanotrees' by controlled seeding. of multiple branching events. Nat. Mater. 3, 380-384.

28. Witten TA and Sander LM (1981) Diffusion-limited aggregation, a kinetic critical phenomenon. Phys. Rev. Lett. 47, 1400-1403.

29. Jacob B and Garik P (1990) The formation of patterns in non-equilibrium growth. Nature. 343, 523-530.
Vol. 5 No. $9 \quad$ (Sep. 2012)

ISSN: 0974- 6846

30. Barkey D, Oberholtzer F and Wu Q (1995) Kinetic Anisotropy and dendritic growth in electrochemical deposition. Phys. Rev. Lett. $75,2980-2983$.

31. Zheng XJ, Jiang ZY, Xie ZX, Zhang SH, Mao BW and Zheng LS, (2007) Growth of silver nanowires by an unconventional electrodeposition without template. Electrochem. Commun. 9(4), 629-632.

32. Rezaei B and Damiri S (2005) Effect of solidification temperature of lead alloy grids on the electrochemical behavior of lead-acid battery. J. Solid State Electrochem. 9, 590-594.
"Lead oxide nanodentrite" http://www.indjst.org
H.R.Ebrahimi et al. Indian J.Sci.Technol. 